\title{
Evaluation of Blended Irrigation Schemes: A Micro-Level Decadal Study of Shrigonda Tahsil in Drought Prone Western Maharashtra, India
}

\author{
Devne Manojkumar ${ }^{1}$, Dhawale Ganesh ${ }^{2 *}$, More Jyotiram ${ }^{2}$ and Mundhe Nitin ${ }^{3}$ \\ ${ }^{1}$ Department of Geography, Sir Parashurambhau College, Pune, India. ${ }^{2 *}{ }^{3}$ Department of Geography, Sir \\ Parashurambhau College, Pune, India. ${ }^{2}$ Department of Geography, BJS Arts Science \& Commerce College, \\ Pune, India.
}

Received: 2019-11-23 Accepted: 2020-04-11

Key words:

Farm Ponds;

Micro-irrigation;

Capacity Building;

Centrally Sponsored Scheme

(CSS);

National Mission on Micro

Irrigation (NMMI).

Correspondent email: gmdhawale@gmail.com

\begin{abstract}
The qualitative parameters of development of a quantitatively increasing population for a resource stressed country like India, is dependent on the sustainability of food availability. Agriculture remains to be a backbone of the economy and food supply. Agriculture, however, in many parts of India, even today, remains to be rain-fed. Recent efforts at the government level, Centre and State, have helped to bring a significant amount of land, initially under rain-fed agriculture, to under irrigation of various types. These varied types of irrigation change regionally; on various agro-factors. Source of water resources to be used for irrigation in the respective climatic sub-regions and the subsequent crop cultivated in the respective region are just a few primary factors controlling the effectivity of the type of irrigation method used. Irrigation requires technological inputs, which, in turn, requires financial expenses that need to be under the significant agro-factors mentioned above. Governments at the Centre and State levels; have been continuously making efforts to support irrigation practices through direct and indirect supportive schemes. These schemes have their positive, and at times, negative impact on the local agriculture at a micro-level. Agriculture is a state subject in India. The Centre does provide finance for various agricultural projects as well. Micro-irrigation has been and will play an essential role in the future in India. Ever since 1992, the government has been taking initiatives in micro-irrigation. These have eventually transpired into schemes, i.e., Centrally Sponsored Scheme (CSS) in 2006, later upgraded to the National Mission on Micro Irrigation (NMMI) implemented since 2013-14 and subsequently National Mission for Sustainable Agriculture. The present study is an attempt to evaluate such 'State' (Central and State Governments)sponsored irrigation programs on agricultural practices at a micro level, over a decade (2005-2016). The study area identified for the same is a tahsil in the Ahmednagar district of Western Maharashtra. What is significant is that, the said tahsil Shrigonda; lies in the drought-prone region and that there have been cyclic variations in the rainfall, and the various agriculture crops cultivated through the last decade. State Government-sponsored schemes are seen to have been blended with Central Government schemes by the local farmers to achieve sustainability of crops. The effects of the same, on the cycle of products, is worth an observation.Human factors also play an equally important role while using the developing Technology of micro-irrigation. Farmers try-and-test various crops with the respective Micro-irrigation technique, in the respective agro-climatic regions, particularly when the source of water is not assured in the drought-prone area. Subsequent allied government schemes (farm ponds), the market value of the product, and perishability or shelf-life of the products also play a significant role in the choice of crop. The success of the micro-irrigation schemes will, however, be dependent on the effective delivery mechanism through close coordination among all the tiers of government and capacity building of beneficiaries.
\end{abstract}

This article is an open access article distributed under the terms and conditions of the Creative Commons

Attribution(CC BY NC) licensehttps://creativecommons.org/licenses/by-nc/4.0/.

\section{Introduction}

Promotion of micro-irrigation has had the objectives of saving water to avoid the looming water crisis (Narayanmoorthy, 2003; Polak et al., 1997; Shah and Kelkar, 2002) and to extend the limited water resource for larger cropped areas during drought times. There happen to be some primary objectives, among others.

Micro-irrigation technologies are seen to bring about an increase in farm incomes through sustained crop yields. There has been a marked motive for state governments of India to popularize micro-irrigation technologies through various systems (Regassa et al., 2005).

Indian population presently stands at 1.37 billion (July 2019), and at this pace, it will rise to 1.60 Billion by 2050 (World Bank Estimates). With limited land and water resources, the increasing population will be a real challenge. Both the resources (Land and Water resources) play a vital role in the Economic sectors and Agriculture in particular, where; water scarcity has the utmost relevance with 18 percent of the world population and only 4 percent the available water resource. Water scarcity is a looming crisis with the 
depletion of available water resources in various ways.

Centrally Sponsored Schemes (CSS) on micro-irrigation, since their inception in 2006 have been able to bring 2 million hectares under micro-irrigation by 2010 . The potential target of 69 million hectares remains a distant dream, however.

Water is one of the most critical inputs for agriculture. The availability of adequate water for irrigation is a crucial factor in attaining higher productivity. However, reduced efficiency of conventional irrigation systems has reduced anticipated outcomes of investment towards water resource development and further aggravated environmental problems like waterlogging and soil salinity, affecting crop yields. Not much work has been identified with reference to the impact of micro-irrigation along with the drought-prone areas in Western Maharashtra. Adaptation and modification of schemes at the Centre and State level would be possible in localized areas only if an impact study of the existing programs is carried out. The specific objectives of the present research study are to evaluate the micro-irrigation schemes in the study area and to suggest a sustainable, integrated method for agricultural development in the study area

The Shrigonda tahsil is located in the southern part of Ahmednagar district. This is a drought-prone area. The tahsil is situated partly in the central part of the Bhima basin. The spatial dimensions of the tahsil are as follows. About $60 \mathrm{Km}$. from east to west and $51 \mathrm{Km}$. from north to south. The maximum height of the tahsil is about $600 \mathrm{~m}$ above the mean sea level. The general slope of the tahsil is north-south, drained by streams like Hanga, Saraswati, and branches of Ghod and Sina rivers. The latitudinal extent is $18^{\circ} 27^{\prime} 18^{\prime \prime}$ to $18^{\circ} 51^{\prime} 54^{\prime \prime}$ North and longitudinal extent is $74^{\circ} 23^{\prime} 24^{\prime \prime}$ to $74^{\circ} 52^{\prime}$ East. It is bounded by Parner and Nagar tahsil to the north, Pune district to the west, and Karjat tahsil to the south-east (Figure 1 ). The population of the study area is about $3,15,975$, according to the 2011 census. There are 114 rural settlements with only one urban center.

\section{The Methods}

\section{Data Aquisition}

A combination of methods makes it possible to vividly define the achieved research goals, which refer to the primary natural and social characteristics of the considered geospace and opportunities for agricultural development. For the data collection related to the analysis of population and settlement, wise farming practices, we used data from Government offices, i.e., Census of India, 2011, State Data Storage Centre (SDSC) Hydrology Project, Nashik and Taluka Krushi Adhikari, Shrigonda Tahsil.

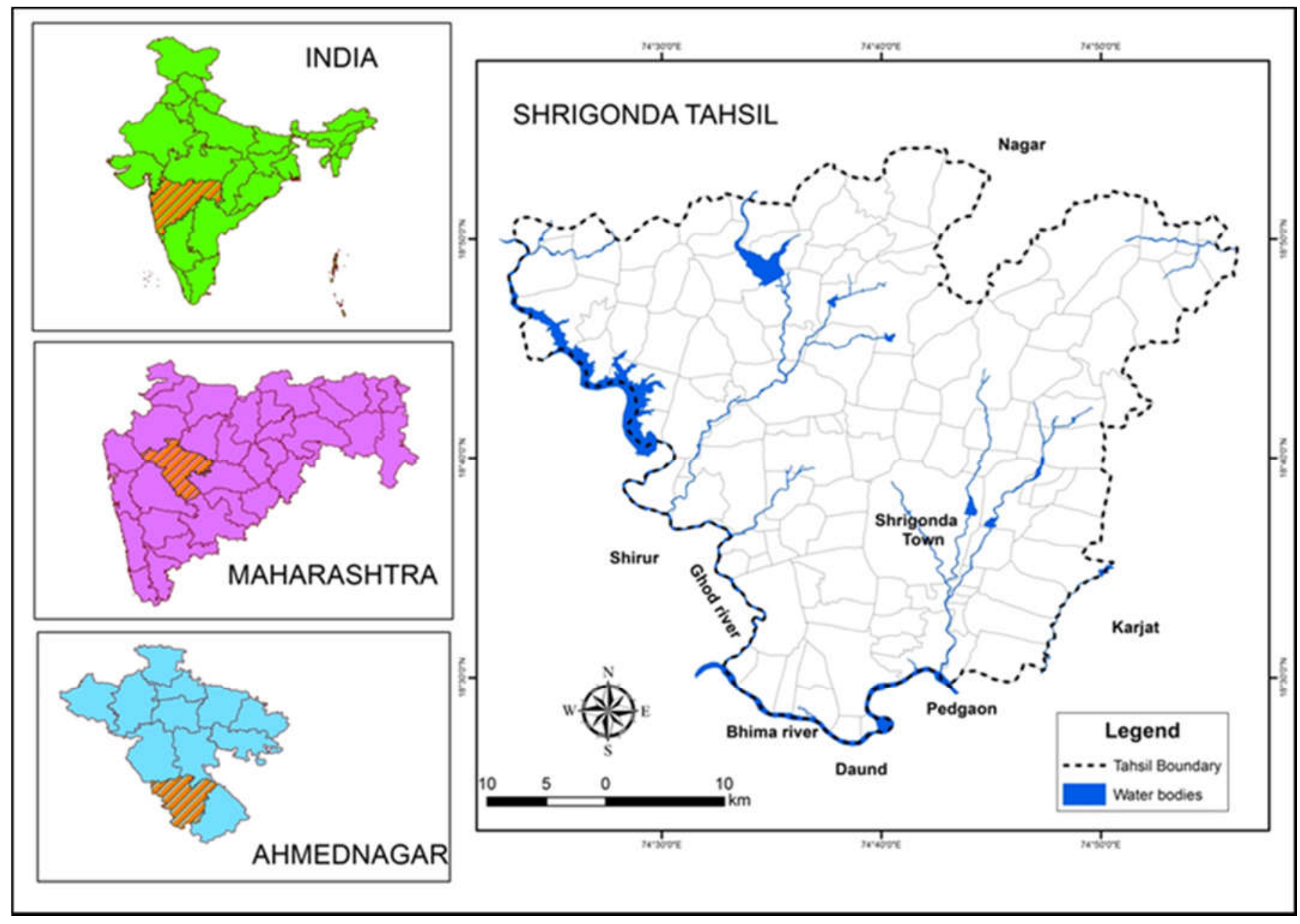

Figure 1. Location Map of the Study Area 


\section{Data Analysis}

The data obtained from various sources was digitized on an open-source platform using QGIS 2.8. LISS IV image of January 2017 was used for land use land cover (LU/LC) analysis. Ground truthing was done using Google Images and physical verification where possible. The core methodological procedure used in this study is the geographical (spatial) method, whose scope of research is related to Shrigonda tahsil. During the investigation, the following techniques have been used, i.e., descriptive, causal, comparative method and theoretical analysis. Descriptive and causal purposes were used to detect the cause consequential link between Microirrigation and agricultural development in Shrigonda tahsil. The methods of theoretical analysis encompassed the theoretical basis and previous work related to the study area.

\section{Result and Discussion}

Rainfall in the study area

Shrigonda tahsil receives an average rainfall of $520 \mathrm{~mm} /$ year. Figure 2 shows amount of average rainfall between 2005-06 and 2015-16 in the study area. It indicates a cycle of crests and troughs with a significant channel during the years 2011-12 and 2012-13.

These average rainfall values have been derived from four weather stations viz. Kashti, Belawandi, Kolgaon, and Mandavgan, which have and West-East orientation, respectively.
As the area lies in the rain shadow of the Western Ghats, the rainfall will decreases from the West towards the East. Thus, the average rainfall at the four weather stations mentioned above to reductions from western-most (Kashti) to the eastern-most (Mandvgaon) village. It is further significant that the western-most communities Kashti and Belawandi, display higher variability as compared to the eastern-most villages of Kolgaon and Mandavgan. It is this variability which impacts the average trend of the rainfall for the region, during the year of 2011-12 and 2012-13.

These variations in rainfall do affect the availability of water available for groundwater recharge and consequently available for micro-irrigation. During years of lower rainfall, the diversion of canal water towards other priority areas like drinking water and industrial use may also impact the availability of water for irrigational purposes.

\section{Micro Irrigation Programme}

Shrigonda tahsil spreads over an area of 160481 hectares, of which 92670 hectares are under agriculture. Thus, nearly 57.74 percent of the area is under agriculture. The cropping season dominantly tends to be Rabi. The approximate number of farmers in this area is around 121,216. This condition is making the per individual holding of farmland minimal, which implements micro-irrigation techniques more uneconomical unless supported by the government.

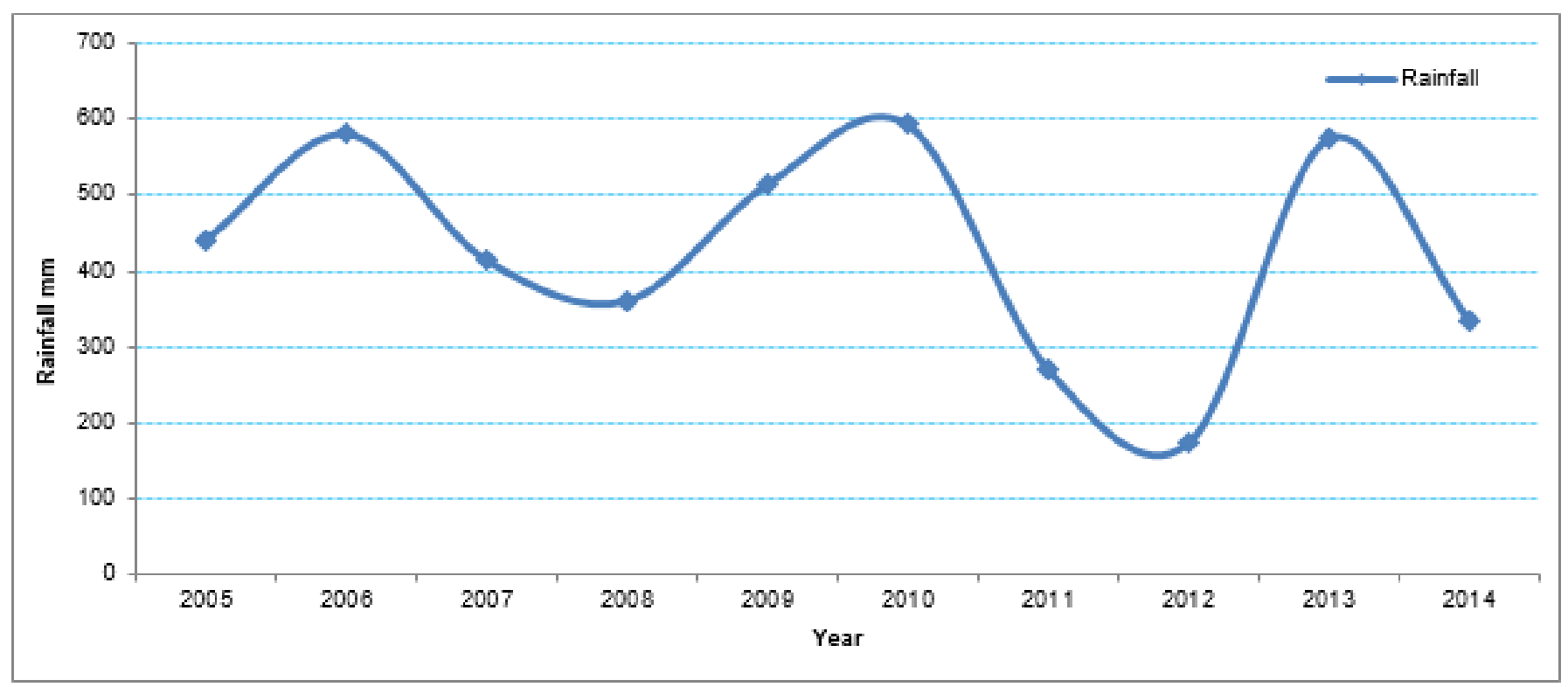

Source: State Data Storage Centre (SDSC) Hydrology Project, Nashik

Figure 2. Rainfall in the study area

Table 1. Area and farmers benefited under NMMI Scheme

\begin{tabular}{crrrrrrrrrrr}
\hline Year & 200 & 200 & 200 & 200 & 200 & 201 & 201 & 201 & 201 & 201 & $2015-16$ \\
& $5-$ & $6-$ & $7-$ & $8-$ & $9-$ & $0-$ & $1-$ & $2-$ & $3-$ & $4-$ & 15 \\
& 06 & 07 & 08 & 09 & 10 & 11 & 12 & 13 & 14 & 15 \\
\hline Farmers & 427 & 184 & 816 & 1448 & 1990 & 1641 & 2564 & 2651 & 925 & 1135 \\
Area ha. & 318 & 138 & 588 & 891 & 1350 & 1156 & 1712 & 1548 & 689 & 724 & 315 \\
\hline
\end{tabular}


Micro-irrigation has generated benefits for the farmers in terms of enhancement of productivity. The average productivity of fruits and vegetables has been seen to increase by 42 and 53 percent, respectively, due to the judicious use of water (Kumar and Sathypriya, 2018). The adjoining Table 1 indicates that the actual area under irrigation between (2005 -06 and 2015-16) and corresponding numbers of farmers that have benefited.

From Table 1, it seems that further indicates a gradual growth in the number of farmers availing the facilities under the micro-irrigation program between 2005-06 to 2012-13. There has, however, been a fall in the number since 2012-13. It can be observed that the number of farmers seeking aid under the Micro Irrigation Programme has been significant during the years of low average rainfall (2011-12 and 201213), where the numbers have crossed 2500 in each of the two years.

Farm ponds and Horticulture

In drought-prone areas, variability in rainfall is high. Thus water resources as a substitute should be readily available in case of a long break in spells or failures of rainfall.

Extracting groundwater and making it available in large storage tanks called 'farm ponds' has been a significant development in the study area since 2008-09. The State government launched a scheme to provide subsidy for the construc- tion of farm ponds, and since, from a number of merely 90 farm ponds in 2008-09, the number of farm ponds in 2018 has grown to more than 2056 .

The water from these farm ponds has been majorly utilized for horticulture. The figure. 3 showing the expanse of the farm ponds overlaps with areas practicing horticulture figure.4. The recent sustenance of Pomegranate and Lemon crops in-spite of the variation in annual precipitation is due to the availability of water resource through farm ponds and micro-irrigation programme.

Impact of MIP on Agricultural Produce.

The major crops for which the micro-irrigation program was utilized in 2005-06 were vegetables and fruits. An exclusive mention needs to be made here for Pomegranate and Lemon, which cumulatively were nearly as much as all other fruit crops put together. Sugarcane was another crop which was to come in favor in the latter phase, but hardly found any takers for the year 2005-06.

The subsequent years (2006-07 and 2007-08) saw a gradual increase of micro-irrigation program being used for sugarcane cultivation till 2008-09 from where it took off exponentially for the next 3 years up to 2011-12. Throughout these three years, the area under sugarcane using microirrigation exceeded the cumulative area under all other crops listed above. Post-2011-12, there has been of fall in the Micro

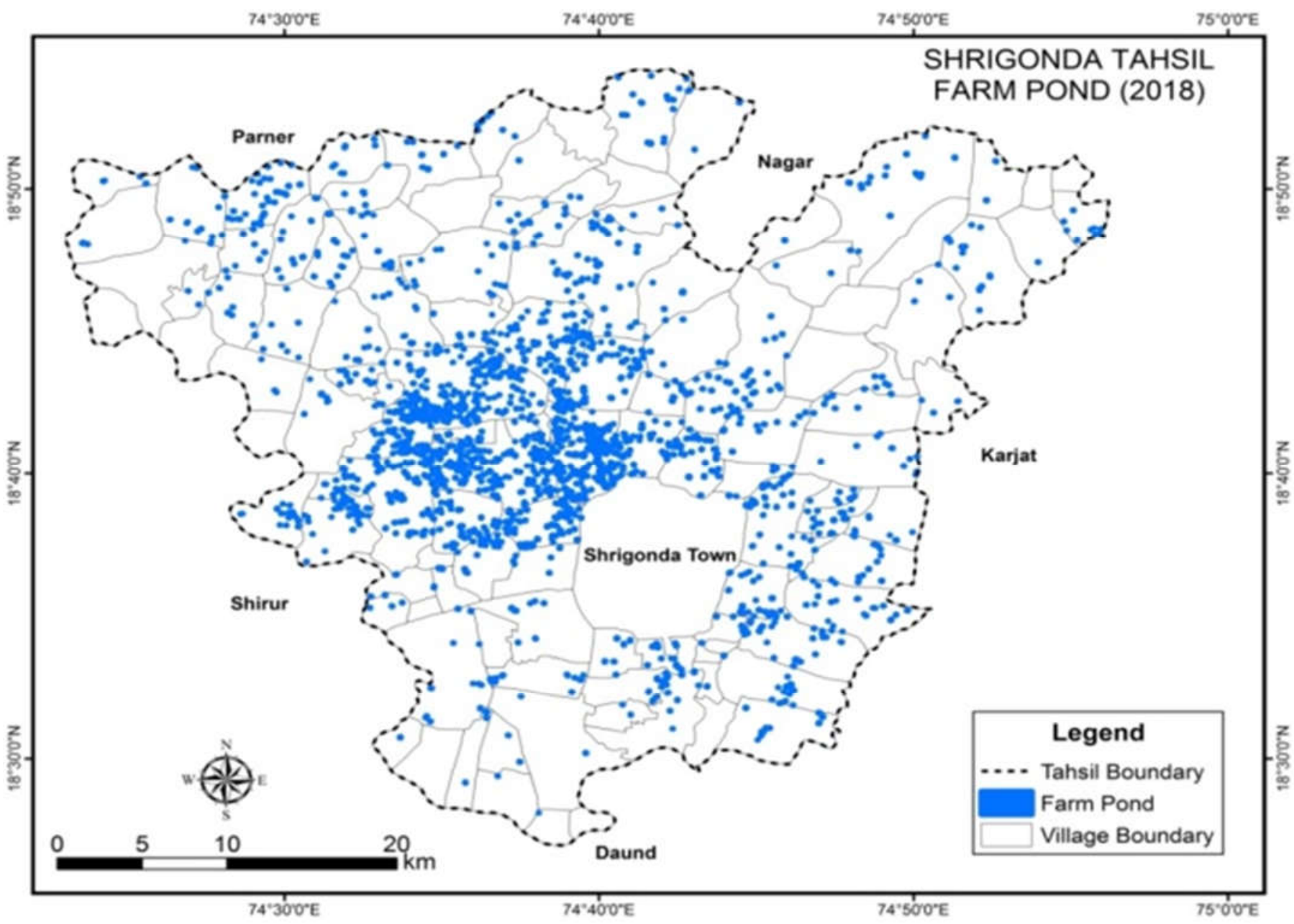

Figure 3. Area under Farm Ponds in the Study Area 


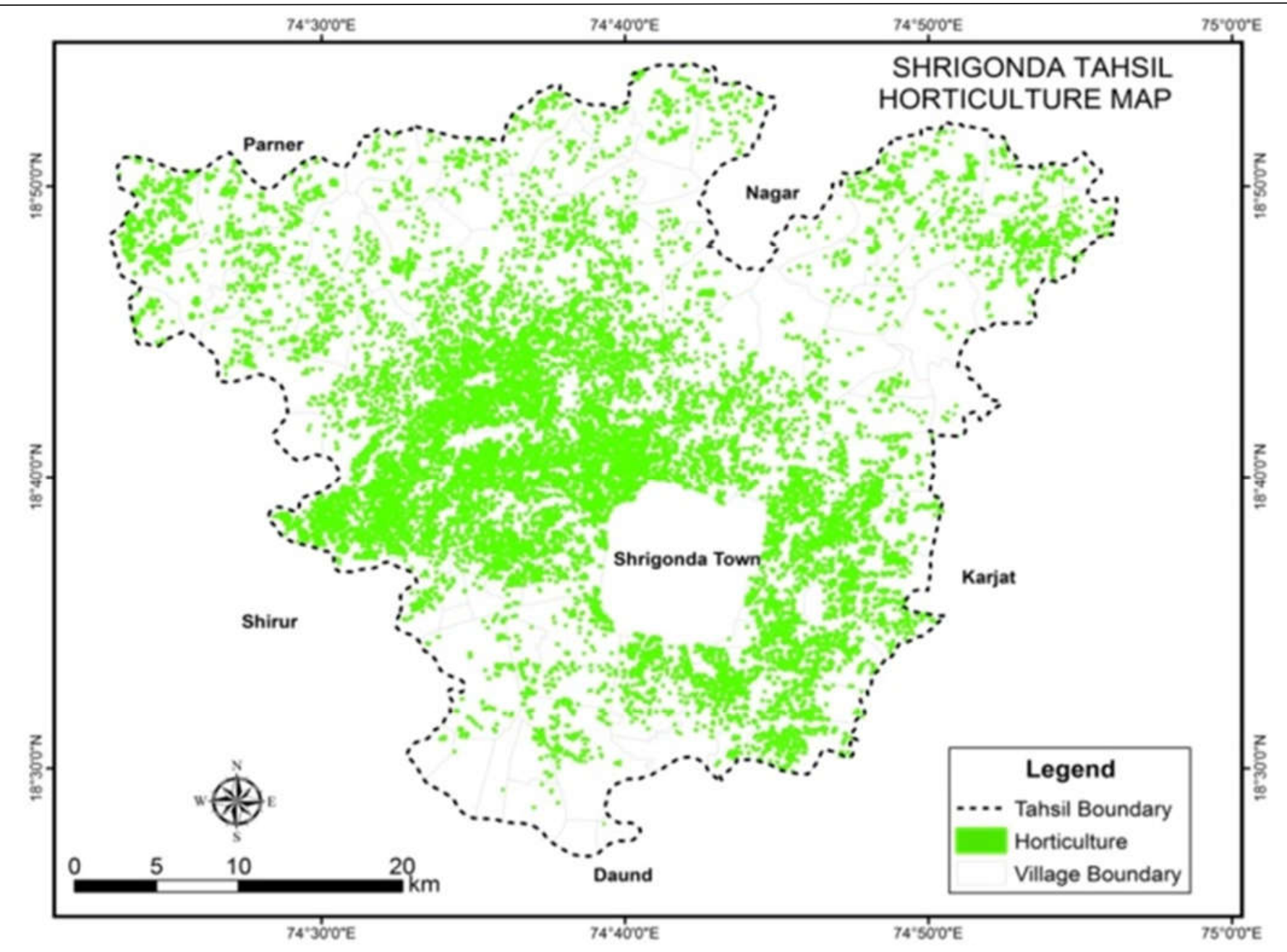

Figure 4. Area under Horticulture in the Study Area

Irrigation Program covering area under sugarcane to reach its second-lowest area of the last decade in 2015-16 to recover back marginally in 2016-17 (Figure 5).

The area under vegetables peaked in 2008-09 but has remained lower since; with the exception of 2011-12 only. The experience of fluctuating market value for vegetables and lower shelf life may have promoted this decrease.

The area under fruits (excluding Pomegranate and Lemon) has remained towards the lower side after the initial spurt for the first four to five years. There seems to be a gradual preferential shift towards Pomegranate and Lemon in the recent past of 5 years since 2011-12, as the two have seemed to have matched the agro-climatic region. The higher market value and shelf life have also aided in this growth.

The areas under Pomegranate and Lemon have remained nearly similar for the last decade. With a few years of exception, the years of high and low also continue to be the same for the two fruit crops. The farmers seem to have maintained the plants due to their sustainability during dry years, higher economic returns, along with a longer shelf life.

Agro climatically the area seems to be sustainable for these two crops which can be seen by their recent dominance, to be exceeded only by sugarcane as the sugar factories in the tahsil (as many as 6) give an assured return to the sugarcane crop which may not, however, sustain for a longer period and may give way to Pomegranate and Lemon cultivation in the near future.

\section{Conclusions}

Thus, blended micro-irrigation schemes at the Centre and State level are seen to generate a synergetic effect to the benefit of local farmers. The sector which has benefited from these blended schemes has been horticulture. Within this, two peculiar fruit crops belonging to the Retaceae (Lemon) and Punicaceae (Pomegranate) are seen to have sustained their respective productive output in the present agroclimatic region, which is a characteristical drought-prone area. Farm ponds in the study region have worked positively to enhance water use efficiency in the 'study area.'

As the study area lies under an identified drought-prone region, in-spite of Blended MIS in the area, rainfall, and consequently, the subsequent recharge of groundwater remains the controlling factors of productivity. Over-extraction of groundwater to recharge the farm ponds may lead to a drastic decrease in the water table. The future growth would be dependent on the capacity building (processing and canning) of the local population. Repeat receipt of grants under MIS for various crops may be possible and may lead to misinterpretation of the data. 


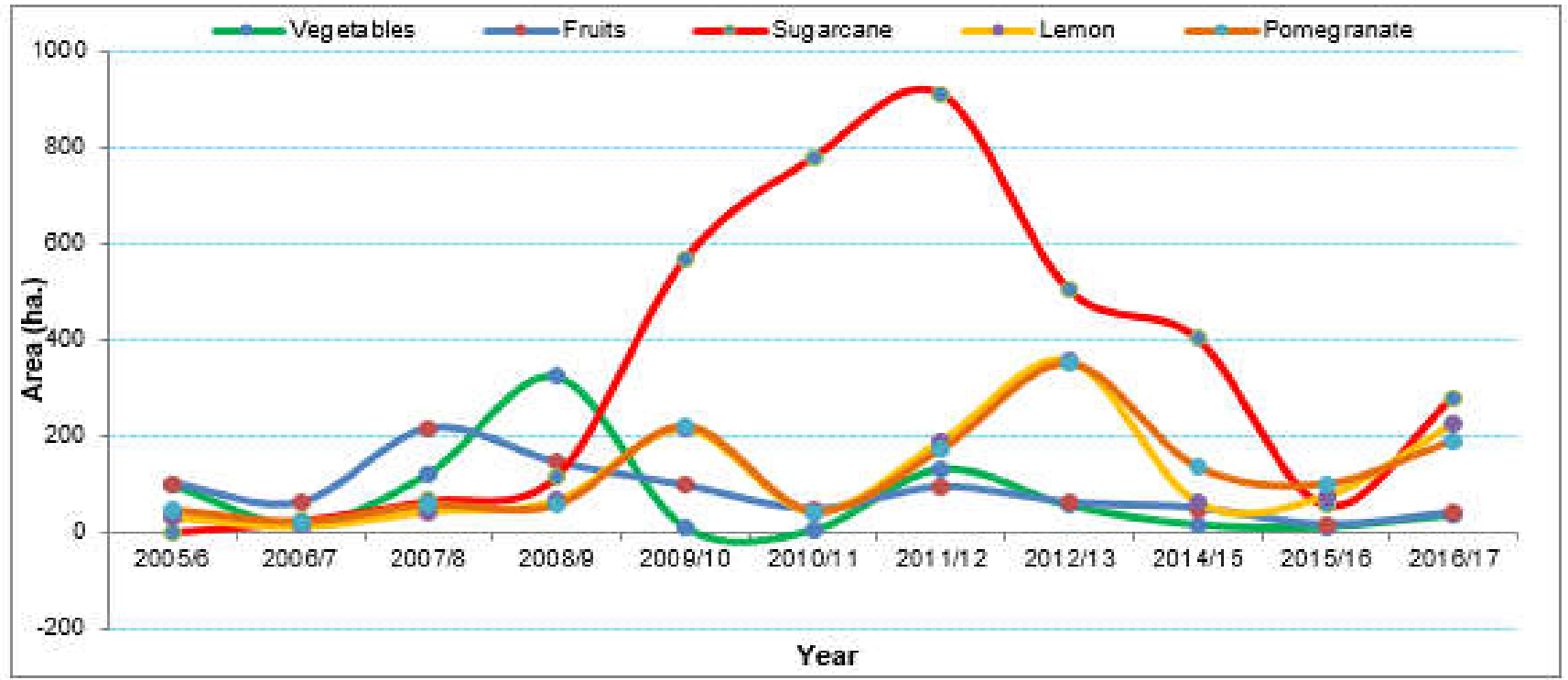

Source:Taluka Krushi Adhikari, Shrigonda Tahsil.

Figure 5. Crops cultivated under NMMI programme in the study area

\section{Acknowledgement}

The authors would like to thank the various Government Offices which made data available for the purpose of this research and the Indian Space Research Organisation (ISRO) for the Satellite Images. Our parent organisation, Sir Parashurambhau College (Autonomous) and the reviewers for the contribution in polishing this manuscript.

\section{Abbreviations:}

CSS: Centrally Sponsored Scheme

et al:And Others

Ha or ha:Hectare

i.e.:That Is

$\mathrm{km}$ :Kilometre

MIP: Micro-Irrigation Programme

MIS: Micro Irrigation schemes

NMMI: National Mission on Micro Irrigation.

viz.: Namely

\&:And

\section{References}

Anwesha, B. \& Pardeep, S. (2010). Agricultural Research In India: An Exploratory Study, International Journal of Social Science \& Interdisciplinary Research, 1(9), 59-77.

Census of India. (2011). Office of the Registrar General \& Census Commissioner, India (ORGI).

Keller, J. (2001). The importance of rural development in the 21stcentury: persistence, sustainability and futures, The future of Australia's country towns, 19-31.

Mahajan, S. \& Bobade, A. (2012). Growth of Nais: A Study of Crop Insurance in India, https://www.researchgate.net/ publication/257929206.

Narayanamoorthy, A. (2003). Averting water crises by drip method of irrigation: A study of two water intensive crops. Indian Journal of Agricultural Economics 58 (3), 42-437.

National Mission on Micro Irrigation, (Operational Guidelines), (2011). Government of India, Ministry of Agriculture, De- partment of Agriculture and Cooperation.

Naveen kumar, M. \& Sathyapriya, E. (2018). Micro irrigation system in Agricultural context - An overview, Conference: National congress on micro irrigation, Water technology centre, TNAU, At Coimbatore.

Polak, P., Nanes, B. \& Adhikari, D. (1997). A low cost drip irrigation system for small farmers in developing countries. Journal of the American Water Resources Association 33 (1), 119 -124 .

Rajović, G. \& Bulatović, J. (2013). Geographical View on Energetic Sources of Climate Northeastern Montenegro, International Letters of Natural Sciences, 3,1-6.

Regassa, E., Namara, B. \& Nagar, R.(2005). Adoption and Impacts of Micro-irrigation Technologies: Empirical Results from Selected Localities of Maharashtra and Gujarat States of India, International Water Management Institute, Colombo, Sri Lanka,1-51.

Shah, T.\& Keller, J. (2002). Micro-irrigation and the poor: A marketing challenge in smallholder irrigation development. In Private irrigation in sub-Saharan Africa: Regional seminar on private sector participation and irrigation expansion in sub-Saharan Africa, 22-26 October 2001, Accra, Ghana. Proceedings, eds. Hilmy Sally and Charles L. Abernethy. Colombo, Sri Lanka, International Water Management Institute, Food and Agriculture Organization of the United Nations, and ACP-EU Technical Centre for Agricultural and Rural Cooperation.

World Bank Estimates accessed online , http://www.worldbank.org/ https://databank.worldbank.org/source/population estimates-and-projections 